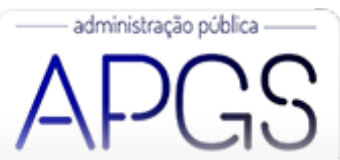

Administração Pública e Gestão Social ISSN: 2175-5787

apgs@ufv.br

Universidade Federal de Viçosa

Brasil

\title{
Distorções Regionais na Distribuição do Fpm: Ûm Estudo Aplicando Conjuntos Fuzzy em Municípios de Minas Gerais
}

Pacheco de Castro, Kleber; da Cruz Lima, Ana Carolina

Distorções Regionais na Distribuição do Fpm: Um Estudo Aplicando Conjuntos Fuzzy em Municípios de Minas

Gerais

Administração Pública e Gestão Social, vol. 12, núm. 1, 2020

Universidade Federal de Viçosa, Brasil

Disponible en: http://www.redalyc.org/articulo.oa?id=351561601002

Esta obra está bajo una Licencia Creative Commons Atribución-NoComercial-SinDerivar 3.0 Internacional. 


\title{
Distorções Regionais na Distribuição do Fpm: Um Estudo Aplicando Conjuntos Fuzzy em Municípios de Minas Gerais
}

\author{
Regional Distortions in The Distribution of Fpm: A Study Applying Fuzzy Sets in Municipalities of Minas Gerais \\ Distorciones Regionales en la Distribución del Fpm: Un Estudio Aplicando Conjuntos Fuzzy en Municipios de \\ Minas Gerais
}

Kleber Pacheco de Castro

Universidade do Estado do Rio de Janeiro, Brasil

Redalyc: http://www.redalyc.org/articulo.oa?

kleberpcastro@gmail.com

Ana Carolina da Cruz Lima

UERJ, Brasil

ana.lima@uerj.br

Recepción: 19 Junio 2017

Aprobación: 19 Marzo 2018

Publicación: 01 Enero 2020

\section{Resumo:}

O Fundo de Participação dos Municípios (FPM) é uma transferência incondicional e redistributiva recebida pelos municípios e oriunda da União. Seus critérios de rateio de recursos apresentam inconsistências que geram uma distribuição pouco equânime dos recursos do fundo. Usando o instrumental matemático dos conjuntos fuzzy, este artigo verificou a relação entre a distribuição do FPM e o nível de necessidade fiscal dos municípios de Minas Gerais entre 2000 e 2010. Constatou-se que a maior parte dos municípios recebe recursos aquém do necessário, que este problema tende a ser maior nas cidades mais populosas e que a distorção se intensificou ao longo do tempo. Os resultados corroboram outras evidências em torno da divisão distorcida do FPM e reforçam a necessidade de revisão de seus critérios.

PalaVRas-CHAVE: federalismo fiscal, transferências intergovernamentais, FPM, Minas Gerais, fuzzy.

\section{Abstract:}

The Municipalities Participation Fund is an unconditional and redistributive transfer received by the municipalitiesfrom the Brazilian federal government. Its resource allocation criteria presents inconsistencies that generate an uneven distribution of fund resources. Using the fuzzy sets mathematical instrument, this paper found a relation between the distribution of the Fund and the level of fiscal demand of the municipalities of the Brazilian state of Minas Gerais between 2000 and 2010. It was verified that most of the municipalities receive less resources than the necessary, that this problem tends to be larger in the most populous cities and that the distortion in the division of the Fund has been intensified over time. The results corroborate other evidence surrounding the distorted division of the FPM and reinforce a need to revise its criteria.

KEYWORDS: fiscal federalism, intergovernmental transfers, FPM, Minas Gerais, fuzzy.

\section{RESUMEN:}

El Fondo de Participación Municipal es una transferencia incondicional y redistributiva recibida por los municipios, oriunda de la Unión. Sus criterios de prorrateo de recursos presentan inconsistencias que generan una distribución poco equitativa de los recursos del fondo. Con el instrumental matemático de los conjuntos fuzzy, este artículo verificó la relación entre la distribución del FPM y el nivel de necesidad fiscal de los municipios de Minas Gerais entre 2000 y 2010 . Se constató que la mayor parte de los municipios reciben recursos por debajo de lo necesario, que este problema tiende a ser mayor en las ciudades más pobladas y que la distorsión se ha intensificado a lo largo del tiempo. Los resultados corroboran otras evidencias en torno a la división distorsionada del fondo y refuerzan la necesidad de revisar sus criterios.

Palabras ClaVe: federalismo fiscal, transferencias intergubernamentales, FPM, Minas Gerais, fuzzy. 


\section{1 - INTRODUÇÃO}

A atual crise fiscal pela qual passa o Estado brasileiro parece ser um momento oportuno para se discutir os problemas relacionados ao federalismo brasileiro e revisar as relaçóes intergovernamentais. Naturalmente, este tipo de debate não pode ser feito de forma isolada, sob pena de se tornar inepto e ineficaz. A condução da política fiscal macroeconômica e a reforma tributária devem não apenas caminhar conjuntamente às tratativas sobre o federalismo, mas, com efeito, liderar o debate e a proposição de reformas deste. Decisões tomadas no nível federal, como renúncia tributária, autorizações excessivas para operações de crédito e elevação das atribuições dos governos subnacionais, desequilibram as relações entre os entes da federação, proporcionando, muitas vezes, resultados regionalmente insatisfatórios na alocação de recursos, bens e serviços públicos (Serra \& Afonso, 2007; Rezende, 2010; Monteiro Neto, 2014). Por isso, a atuação conjunta (vertical e horizontalmente) cooperativa entre diferentes governos pode reduzir efeitos adversos de políticas tomadas isoladamente, aproveitando a sinergia estabelecida entre esses governos (Ter-Minassian \& Mello, 2016).

Além da crise federal, estados e municípios também passam por uma situação de desequilíbrio orçamentário grave. Alguns governos estaduais e prefeituras já atingiram um patamar de instabilidade fiscal muito elevado, estando estes próximos de uma situação de insolvência (Secretaria do Tesouro Nacional [STN], 2016a; Federação das Indústrias do Estado do Rio de Janeiro [FIRJAN], 2017). Constata-se, inclusive, que esta desigualdade ocorre nas escalas vertical e horizontal, ou seja, entre entes do mesmo nível de governo. Esta distância está relacionada a uma gestão eficiente ou não de recursos por seus administradores e à fiscalização e transparência no uso dos mesmos. Contudo, a distribuição inadequada de recursos parece ser o principal determinante desta "equação".

Tendo isso em vista, um dos pontos nevrálgicos inseridos na questão do federalismo brasileiro é a partilha de recursos entre os três níveis governo. Essa partilha é comumente denominada de "transferências intergovernamentais" e compreende um fluxo de recursos obrigatórios ou não de um nível de governo (União, estado e município) a outro. A maior parte das transferências constitucionais intergovernamentais tem caráter obrigatório e seu montante está vinculado à arrecadação de determinados tributos. Pode-se citar como exemplo o Fundo de Participação dos Estados (FPE), o Fundo de Participação dos Municípios (FPM), a Cota-Parte do Imposto sobre a Circulação de Mercadorias e Serviços (ICMS) e a Contribuição de Intervenção no Domínio Econômico (CIDE) Combustíveis.

Este artigo se propõe a analisar apenas uma destas transferências, o FPM. Com a imposição desta restrição, pretende-se trazer a análise exclusivamente para o nível municipal, verificando a distribuição dos recursos deste fundo entre cidades. A escolha deste fundo se baseia na importância dele para a sobrevivência de diversas localidades (Gomes \& Macdowell, 2000), especialmente aquelas com pouca atividade econômica e que encontram-se geograficamente distantes de centros econômicos mais dinâmicos. De acordo com Afonso e Castro (2016), em 2014, o FPM transferiu recursos no montante da ordem de 1,13\% do Produto Interno Bruto (PIB), o que significou para os municípios aproximadamente $17,6 \%$ de sua receita disponível ${ }^{[\mathrm{i}]}$ (cerca de $\mathrm{R} \$ 64,2$ bilhões, a preços correntes).

Apesar de o volume de recursos partilhados via FPM ser significativo (superior à arrecadação da Contribuição Social sobre o Lucro Líquido - CSLL - no mesmo ano, que foi de R\$61,6 bilhões) ${ }^{[i i]}$, sua distribuição responde a critérios ultrapassados (os quais serão descritos na próxima seção) e, por isso, não reflete a real necessidade dos municípios, no que diz respeito ao tamanho do orçamento vis-à-vis os problemas (demandas) com os quais se defrontam, sendo este o problema que motiva a elaboração deste estudo. Desta forma, a hipótese assumida neste artigo é de que o FPM apresenta um padrão de distribuição pouco equalizador, não visando o diferencial de necessidade das diversas localidades. (Error 1: La referencia debe estar ligada) (Error 2: El tipo de referencia es un elemento obligatorio) (Error 3: No existe una URL relacionada) 
Tendo em vista esse cenário, o objetivo deste trabalho é verificar se o FPM apresenta distorções na sua distribuição regional, considerando, para isso, o nível de demanda orçamentária, a capacidade de geração de recursos próprios e o repasse de transferências intergovernamentais em cada município. Para alcançar tal objetivo, será aplicado o instrumental matemático da teoria dos conjuntos fuzzy - também conhecida como teoria dos conjuntos nebulosos - aos municípios do estado de Minas Gerais.

Espera-se que os resultados apontem as características das regióes mais ou menos beneficiadas pelo fundo, de tal sorte que concatenem com os pressupostos teóricos e com a literatura prévia. Tal constatação contribuiria para um eventual redesenho dos critérios de partilha do fundo.

Além desta seção introdutória, este artigo possui mais quatro seções: A segunda seção apresenta as características gerais do FPM e os problemas inerentes às suas regras de partilha entre municípios; a terceira detalha a metodologia aplicada, a abordagem teórica fuzzy, as variáveis selecionadas e os limites geográfico e temporal utilizados; a quarta apresenta os resultados obtidos, explanando-os a partir de duas óticas (resultados agregados e individuais). Na quinta seção são realizadas as considerações finais do artigo.

\section{2 - O FPM E SUAS DISTORÇÕES}

As transferências intergovernamentais têm um peso significativo na determinação do orçamento dos governos subnacionais, sendo um dos sustentáculos do federalismo fiscal brasileiro. Tal característica tem relação com o nível de capilaridade dos serviços públicos e, consequentemente, de autonomia fiscal que é atribuída aos governos locais (Afonso, Soares \& Castro, 2013). Em um país de dimensões continentais, no qual se requer uma ampla difusão da presença do poder público, justifica-se a existência de um Estado descentralizado como o brasileiro.

Ao mesmo tempo em que a distribuição de recursos para níveis de governo mais baixos proporciona um ganho para a população local, através da criação de políticas públicas personalizadas e da proximidade entre gestores públicos e residentes, há evidência de "perdas" em outras dimensões, como: Sobreposição de competências (Boadway, Roberts \& Shah, 1993), menor controle sobre o uso de recursos públicos, adoção de medidas descoordenadas entre os diferentes níveis de governo e desequilíbrio horizontal na distribuição de recursos (Afonso, 1994). Sobre esse último ponto, enquadram-se as transferências do FPE e do FPM.

Por se tratarem de transferências "incondicionais redistributivas" - ou seja, não exigem contrapartida pelo órgão receptor e adotam critérios que visam a equidade na repartição de recursos -, o FPE e o FPM não deveriam apresentar distorções na divisão de seus fluxos. Porém, este problema existe e não é recente. Acerca desse tema (FPM), um estudo de meados da década de 1990, apenas poucos anos após a edição da lei ${ }^{\text {[iii] }}$ que regulamentou a partilha do fundo, já apontava nesta direção: “[...] o FPM é, atualmente, mal distribuído. Os atuais critérios de partilha não são capazes de direcionar os recursos para os municípios que, frente aos gastos pelos quais são responsáveis, realmente necessitam de complementação financeira às suas receitas próprias", (Mendes, 1994, pp. 7-8).

Determinado pela mesma legislação, o cenário para o FPE não era diferente, haja vista seu perfil estático, que não levava em conta mudanças no perfil socioeconômico dos estados ao longo do tempo. Não por acaso, em 2010, o Supremo Tribunal Federal (STF), através da Ação Direta de Inconstitucionalidade (ADI) $n^{\circ}$ 875, declarou inconstitucional o critério de partilha do FPE previsto na Lei Complementar $n^{\circ} 62$ de 1989 (LC 62/89), determinando que o Congresso Nacional aprovasse nova regra até 31 de dezembro de 2012.

O resultado desta determinação foi a Lei Complementar $n^{\circ} 143$ de $2013^{\text {[iv] }}$ (LC 143/13), que alterou a partilha do FPE a partir de $1^{\circ}$ de janeiro de 2016. Esta lei, entretanto, mostra-se inócua na medida em que, na prática, altera marginalmente a distribuição dos recursos entre os estados da federação[v], como aponta Souza Neto e Ferreira (2015). A Tabela 01 mostra a distribuição prevista para 2016. 
Tabela 1 - Projeção de Distribuição do FPE em R\$ Milhões Correntes - 2016

\begin{tabular}{|c|c|c|c|c|}
\hline $\begin{array}{l}\text { Unidade da } \\
\text { Federação }\end{array}$ & $\begin{array}{l}\text { Estimativa } \\
\text { de } \\
\text { distribuição } \\
\text { pelo } \\
\text { critério da } \\
\text { LC } 62 / 89\end{array}$ & $\begin{array}{l}\text { Estimativa } \\
\text { de } \\
\text { distribuição } \\
\text { pelo } \\
\text { critério da } \\
\text { LC } \\
143 / 2013\end{array}$ & $\begin{array}{l}\text { Estimativa } \\
\text { Total para } \\
\text { o FPE } \\
2016\end{array}$ & $\begin{array}{l}\text { Participação } \\
\text { da } \\
\text { estimativa } \\
\text { de } \\
\text { distribuição } \\
\text { pelo critério } \\
\text { da LC } \\
143 / 2013 \\
\text { no total (\%) }\end{array}$ \\
\hline Acre & $2.087,09$ & 24,29 & $2.111,38$ & $1,16 \%$ \\
\hline Alagoas & $2.538,00$ & 28,42 & $2.566,43$ & $1,12 \%$ \\
\hline Amapá & $2.081,60$ & 22,25 & $2.103,85$ & $1,07 \%$ \\
\hline Amazonas & $1.702,37$ & 25,98 & $1.728,35$ & $1,53 \%$ \\
\hline Bahia & $5.732,46$ & 51,50 & $5.783,95$ & $0,90 \%$ \\
\hline Ceará & $4.476,11$ & 41,13 & $4.517,24$ & $0,92 \%$ \\
\hline $\begin{array}{l}\text { Distrito } \\
\text { Federal }\end{array}$ & 421,08 & 4,04 & 425,12 & $0,96 \%$ \\
\hline $\begin{array}{l}\text { Espírito } \\
\text { Santo }\end{array}$ & 915,12 & 12,84 & 927,97 & $1,40 \%$ \\
\hline Goiás & $1.734,53$ & 17,58 & $1.752,11$ & $1,01 \%$ \\
\hline Maranhão & $4,403,70$ & 43,17 & $4.446,87$ & $0,98 \%$ \\
\hline Mato Grosso & $1.408,01$ & 12,54 & $1.420,55$ & $0,89 \%$ \\
\hline $\begin{array}{l}\text { Mato Grosso } \\
\text { do Sul }\end{array}$ & 812,63 & 10,98 & 823,61 & $1,35 \%$ \\
\hline $\begin{array}{l}\text { Minas } \\
\text { Gerais }\end{array}$ & $2.717,61$ & 28,00 & $2.745,61$ & $1,03 \%$ \\
\hline Pará & $3.728,82$ & 38,83 & $3.767,65$ & $1,04 \%$ \\
\hline Paraíba & $2.921,62$ & 27,55 & $2.949,17$ & $0,94 \%$ \\
\hline Paraná & $1.758,99$ & 14,72 & $1.773,71$ & $0,84 \%$ \\
\hline Pernambuco & $4.209,69$ & 35,29 & $4.244,98$ & $0,84 \%$ \\
\hline Piauí & $2.636,41$ & 26,41 & $2.662,82$ & $1,00 \%$ \\
\hline $\begin{array}{l}\text { Rio de } \\
\text { Janeiro }\end{array}$ & 932,02 & 18,74 & 950,76 & $2,01 \%$ \\
\hline $\begin{array}{l}\text { Rio Grande } \\
\text { do Norte }\end{array}$ & $2.548,86$ & 25,94 & $2.574,80$ & $1,02 \%$ \\
\hline $\begin{array}{l}\text { Rio Grande } \\
\text { do Sul }\end{array}$ & $1.436,62$ & 9,36 & $1.445,99$ & $0,65 \%$ \\
\hline Rondônia & $1.717,75$ & 21,92 & $1.739,67$ & $1,28 \%$ \\
\hline Roraima & $1.513,43$ & 17,02 & $1.530,45$ & $1,12 \%$ \\
\hline $\begin{array}{l}\text { Santa } \\
\text { Catarina }\end{array}$ & 780,78 & 9,24 & 790,02 & $1,18 \%$ \\
\hline São Paulo & 610,08 & 4,64 & 614,72 & $0,76 \%$ \\
\hline Sergipe & $2.535,08$ & 22,12 & $2.557,20$ & $0,87 \%$ \\
\hline Tocantins & $2.647,76$ & 21,77 & $2.669,53$ & $0,82 \%$ \\
\hline TOTAL & $61.008,26$ & 616,25 & $61.624,50$ & $1,01 \%$ \\
\hline \multicolumn{5}{|l|}{ Fonte: STN. } \\
\hline
\end{tabular}

Observa-se que, em média, apenas 1\% da previsão de recursos a serem transferidos pelo fundo em 2016 respondem aos critérios da nova legislação, permanecendo vinculados ao critério estático os $99 \%$ restantes.

A explicação básica para tal comportamento reside nos critérios determinados pela nova legislação:

[...] para cada decêndio a partir de 2016, os valores que as unidades federativas receberam no correspondente decêndio do exercício de 2015 será corrigido pela variação acumulada do IPCA e por $75 \%$ da variação real do PIB do ano anterior ao da distribuição. Com isso, cria-se um valor de referência que separará dois critérios de distribuição. Caso o percentual da arrecadação líquida do IR e IPI destinado ao FPE seja inferior ao valor de referência, o valor será integralmente distribuído 
de acordo com os coeficientes fixos constantes do anexo da Lei Complementar (LC) 62/89. No entanto, se o montante a ser distribuído superar o valor de referência, a parcela excedente será distribuída conforme os novos critérios estabelecidos no inciso III da LC 143/13 (Secretaria do Tesouro Nacional [STN], 2016b, p.3).

Devido à crise econômica e fiscal brasileira, a arrecadação recente de imposto de renda (IR) e imposto sobre produtos industrializados (IPI) sofreu uma redução (Afonso, Pinto \& Guimarães Junior, 2017), não permitindo ao fundo adotar uma distribuição mais justa dos recursos. De fato, apenas com um cenário de crescimento econômico razoável e regular, no qual a elasticidade da tributação com relação ao PIB fosse maior que 1 (um), seria possível observar uma melhor distribuição do FPE ao longo do tempo.

Além de ter efeito praticamente nulo na partilha do FPE, a Lei Complementar (LC) 143/13 manteve inalterada as regras de distribuição do FPM, mantendo o status quo deste fundo, o qual será detalhado a seguir.

\section{1 - Característica Gerais do FPM}

Regulamentado através do Artigo 91 do Código Tributário Nacional ${ }^{[\mathrm{vi}]}$ (CTN), o FPM passou a ser formalmente distribuído aos municípios em 1967, tendo seus recursos vinculados à arrecadação do IR e do IPI. A criação de uma transferência de caráter incondicional e redistributivo, com recursos oriundos da União e destinados aos municípios, contudo, remonta à Constituição de $1946^{[\mathrm{vii}]}$. É curioso notar que, apesar do viés centralizador do governo militar, o FPM não foi revogado quando da elaboração do CTN e da promulgação da Constituição de 1967 (Mendes, Miranda \& Cosio, 2008).

Os sucessivos aumentos da participação do fundo na arrecadação do IR e do IPI, que passou de $10 \%$ à época do CTN para $23,5 \%$ a partir de setembro de $2007^{\text {[viii] }}$, permitiram que esta se tornasse a segunda maior transferência constitucional em vigor no país. De acordo com informações de Afonso e Castro (2016), em 2014 apenas a Cota-Parte do ICMS movimentou mais recursos do que o FPM: 1,31\% do PIB versus 1,13\% do PIB, respectivamente.

Sua distribuição não é feita da mesma forma para todos os "níveis" de municípios. Há uma segmentação dos recursos antes da aplicação dos critérios de distribuição: 10\% são dedicados às 27 (vinte e sete) capitais (FPM Capitais), 86,4\% atendem aos demais municípios (FPM Interior) e 3,6\% constituem uma reserva a atender os municípios mais populosos[ix], que não são capitais (FPM Reserva).

Apesar de as capitais usualmente terem o maior contingente populacional dos estados, algumas características destas permitem verificar uma menor vulnerabilidade (dependência) com relação ao FPM: São centros econômicos de seus respectivos estados, tendo, portanto, maior independência financeira; possuem uma parcela exclusiva do FPM, estando menos sujeitos a perdas decorrentes de alterações populacionais de outros municípios; e possuem um critério de rateio do FPM dinâmico e mais justo, que engloba a participação populacional da capital na população total das capitais e o inverso da relação da renda per capita do estado onde se localiza a capital com a renda per capita do Brasil.

Tendo em vista esta característica diferenciada, a análise do FPM neste trabalho será restrita ao FPM Interior, por este representar a maior parte do fundo, apresentar os principais problemas de distribuição e estar relacionado às localidades com maior risco fiscal e vulnerabilidade socioeconômica (Mendes, 1994). Deve-se destacar que o FPM Reserva tem um mecanismo de cálculo semelhante ao do FPM Capitais, porém, seu repasse é dedicado a uma parcela dos municípios que também recebe do FPM Interior, dificultando, assim, a diferenciação das duas rubricas nos municípios populosos, que não capital.

Tendo em vista que a LC 143/13 não tratou de nenhuma modificação na partilha do FPM, suas regras atuais ainda são determinadas pela LC 62/89. Basicamente, deve-se seguir a seguinte orientação para calcular o FPM a ser recebido por determinado município: Primeiro, verificar em que unidade federativa o município se localiza e obter a participação que este estado tem no total do fundo (Tabela 02), e segundo, verificar a 
população da cidade e obter o seu coeficiente populacional (Tabela 03), que, por sua vez, dará a participação desse município dentro de seu estado.

Tabela 2 - FPM Interior: Participação dos Estados no Total a Partilhar

$\begin{aligned} & \text { Tabela } 2 \text { - FPM Interior: Participação dos Estados no } \\
& \text { Total a Partilhar }\end{aligned}$
\begin{tabular}{llll}
\hline UF & $\begin{array}{l}\text { Participação } \\
\text { \% }\end{array}$ & UF & $\begin{array}{l}\text { Participação } \\
\text { \% }\end{array}$ \\
\hline AC & 0,2630 & RN & 2,4324 \\
\hline AM & 1,2452 & SE & 1,3342 \\
\hline AP & 0,1392 & DF & 0,0000 \\
\hline PA & 3,2948 & GO & 3,7318 \\
\hline RO & 0,7464 & MS & 1,5004 \\
\hline RR & 0,0851 & MT & 1,8949 \\
\hline TO & 1,2955 & ES & 1,7595 \\
\hline AL & 2,0883 & MG & 14,1846 \\
\hline BA & 9,2695 & RJ & 2,7379 \\
\hline CE & 4,5864 & SP & 14,2620 \\
\hline MA & 3,9715 & PR & 7,2857 \\
\hline PB & 3,1942 & SC & 4,1997 \\
\hline PE & 4,7952 & RS & 7,3011 \\
\hline PI & 2,4015 & TOTAL & 100,0000 \\
\hline Fonte: Resoluçẵo TCU n & & \\
242 de 1990. & & & \\
\hline
\end{tabular}

Fonte: Resolução TCU n 242 de 1990.

Tabela 3 - FPM Interior: Coeficientes por Faixa Populacional

\begin{tabular}{|c|c|c|c|}
\hline \multicolumn{4}{|c|}{$\begin{array}{l}\text { Faixa Populacional } \\
\text { Ponulacão Coficiente Ponulacão }\end{array}$} \\
\hline até 10.188 & 0,6 & $\begin{array}{l}\text { de } 61.129 \mathrm{a} \\
71.316\end{array}$ & 2,4 \\
\hline $\begin{array}{l}\text { de } 10.189 \mathrm{a} \\
13.584\end{array}$ & 0,8 & $\begin{array}{l}\text { de } 71.317 \mathrm{a} \\
81.504\end{array}$ & 2,6 \\
\hline $\begin{array}{l}\text { de } 13.585 \mathrm{a} \\
16.980\end{array}$ & 1,0 & $\begin{array}{l}\text { de } 81.505 \text { a } \\
91.692\end{array}$ & 2,8 \\
\hline $\begin{array}{l}\text { de } 16.981 \mathrm{a} \\
23.772\end{array}$ & 1,2 & $\begin{array}{l}\text { de } 91.693 \mathrm{a} \\
101.880\end{array}$ & 3,0 \\
\hline $\begin{array}{l}\text { de } 23.773 \mathrm{a} \\
30.564\end{array}$ & 1,4 & $\begin{array}{l}\text { de } 101.881 \mathrm{a} \\
115.464\end{array}$ & 3,2 \\
\hline $\begin{array}{l}\text { de } 30.565 \text { a } \\
37.356\end{array}$ & 1,6 & $\begin{array}{l}\text { de } 115.465 \mathrm{a} \\
129.048\end{array}$ & 3,4 \\
\hline $\begin{array}{l}\text { de } 37.357 \text { a } \\
44.148\end{array}$ & 1,8 & $\begin{array}{l}\text { de } 129.049 \mathrm{a} \\
142.632\end{array}$ & 3,6 \\
\hline $\begin{array}{l}\text { de } 44.149 a \\
50.940\end{array}$ & 2,0 & $\begin{array}{l}\text { de } 142.633 \text { a } \\
156.216\end{array}$ & 3,8 \\
\hline $\begin{array}{l}\text { de } 50.941 \mathrm{a} \\
61.128\end{array}$ & 2,2 & $\begin{array}{l}\text { acima de } \\
156.216\end{array}$ & 4,0 \\
\hline $\begin{array}{l}\text { Fonte: Decret } \\
\text { de } 1981 .\end{array}$ & $\mathrm{n}^{\circ} 1.881$ & & \\
\hline
\end{tabular}

Fonte: Decreto Lei n ${ }^{\circ} 1.881$ de 1981.

Para se obter a cota de município deve-se aplicar as seguintes fórmulas: 
$\mathrm{FPM}_{k}$ - valor a ser distribuído ao estado $\mathrm{k}$

FPM $_{\text {Total }}$ - valor total a ser distribuído;

$\beta_{k}$ - participação do estado $\mathrm{k}$ no total a ser distribuído;

$\mathrm{FPM}_{j}^{k}$ - valor a ser distribuído ao município $\mathrm{j}$, do estado $\mathrm{k}$;

$\lambda_{j}^{k}$ - coeficiente populacional do município $\mathrm{j}$, do estado $\mathrm{k}$; e

$\sum \lambda_{k}$-somatório dos coeficientes dos municípios do estado $\mathrm{k}$.

$$
\begin{gathered}
\mathrm{FPM}_{k}=0,864 \times \mathrm{FPM}_{\text {Total }} \times \beta_{k} \\
\mathrm{FPM}_{j}^{k}=\frac{\mathrm{FPM}_{k} \times \lambda_{j}^{k}}{\sum \lambda^{k}}
\end{gathered}
$$

Independentemente do tipo de segmentação do FPM, o cálculo dos coeficientes das cidades é realizado anualmente pelo Tribunal de Contas da União (TCU). A responsabilidade pelo fornecimento dos dados que subsidiam os cálculos do TCU é do IBGE. Todo ano o IBGE tem a incumbência de estimar a população de cada município e também a renda per capita dos estados, informando-os ao TCU. Os municípios, por sua vez, podem contestar estas estimativas, cabendo ao IBGE o acolhimento ou não dos pleitos. São cada vez mais comuns decisões judiciais que determinam a alteração dessas estimativas, as quais são especificadas pelo TCU quando da divulgação dos coeficientes (TCU, 2016).

\section{2 - Principais Problemas do FPM}

\subsection{1 - Critério de Rateio Estático}

O primeiro e principal problema do FPM remete a ADI 875 do STF, citada previamente. A linha de argumentação daquela decisão, para apontar a inconstitucionalidade da partilha do FPE, girava em torno do fato deste ter um critério estático de distribuição definido de maneira arbitrária, através de um acordo político. A LC 62/89, que definiu tais critérios, previa uma mudança nos mesmos a partir de $1992^{[\mathrm{x}]}$, porém, tal previsão só se concretizou com a LC 143/13, por força da determinação do Supremo Tribunal Federal (STF).

De acordo com o relator do caso no STF, ministro Gilmar Mendes, os fundos de participação deveriam promover o equilíbrio socioeconômico entre as unidades da federação. Este objetivo só seria alcançado através de revisões periódicas dos coeficientes, "de modo a se avaliar criticamente se os até então adotados ainda estão em consonância com a realidade econômica dos entes federativos e se a política empregada na distribuição dos recursos produziu o efeito desejado" ${ }^{[x i]}$. Dito de outra forma, os critérios deveriam acompanhar as mudanças no perfil social, econômico e demográfico das unidades da federação. A decisão, exclusiva ao FPE, é plenamente extensível ao FPM Interior, na medida em que este também utiliza a tabela estática de divisão de recursos entre os estados (Tabela 2).

Seria de se esperar que, a partir do momento que o FPE alterasse suas regras e passasse a utilizar um critério dinâmico e mais justo, o mesmo movimento se verificaria no FPM Interior, isto é, os municípios, assim como os estados, demandariam do STF uma avaliação sobre a constitucionalidade do critério de rateio do fundo. Porém, como ainda não se verifica, na prática, uma mudança de distribuição do FPE, não há perspectivas de mudanças no FPM Interior.

\subsection{2 - Adoção de Faixas Populacionais}

O tamanho da população é o único critério para a distribuição dos recursos do FPM dentro de um determinado estado. Assume-se que municípios que possuem uma população maior têm maior demanda por recursos, estando aptos, portanto, a receber uma parcela maior do fundo. Apesar de a ideia ser justa, sua 
execução não o é. Ao invés de adotar uma função contínua para diferenciar demograficamente os municípios, optou-se por trabalhar com faixas populacionais discretas (Tabela 03).

Esta escolha proporciona pelo menos um grave problema: Permite que municípios com populações diferentes recebam o mesmo coeficiente populacional, concedendo o mesmo volume de recursos do fundo, caso esses municípios estejam no mesmo estado. Por exemplo, em 2010, Bela Vista de Minas (MG), com 10.004 habitantes, teria a mesma participação no FPM que Serra da Saudade (MG), com 815 habitantes. Ou seja, fica relegado ao segundo plano qualquer critério de justiça distributiva a partir daí.

É fácil notar que o estabelecimento desta regra "incentiva” um município a ter uma população próxima dos limites inferiores das faixas populacionais. Desta distorção decorrem outros problemas sérios, como o aumento explosivo do número de pequenos municípios no país, fenômeno identificado no Brasil entre as décadas de 1980 e 1990 (Gomes \& Macdowell, 2000; Brandt, 2010), e a distorção de dados populacionais de pequenos municípios (Monastério, 2014). Há ainda o problema da falta de atualização destas faixas populacionais discretas, prejudicando especialmente as cidades mais populosas e as que viram seu número de habitantes crescer fortemente nas duas últimas décadas, como as cidades médias.

A consequência direta desses problemas é uma ineficiência distributiva, o que este artigo pretende mostrar. Mesmo quando comparado à única variável presente nas três modalidades de FPM - população -, evidenciase uma distribuição bastante questionável, o que pode ser observado na Figura 1.

Figura 1 - FPM per capita x População - 2014

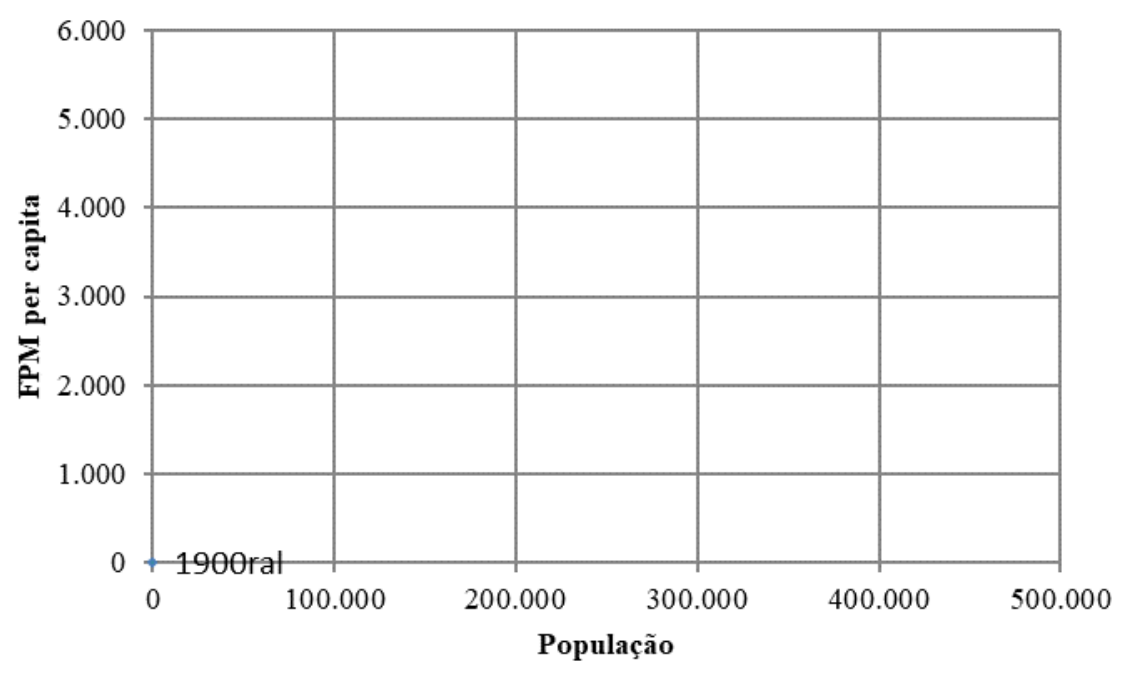

Elaboração própria. Fonte primária: Finbra/STN.

O gráfico de dispersão (Figura 1) dá uma boa dimensão da ineficiência distributiva alcançada pelo FPM: Há uma relação negativa entre o FPM per capita e o tamanho da população, observados nos municípios brasileiros em 2014. Enquanto as cidades pequenas, com menos de 10.000 habitantes, obtêm um volume de recursos relativamente alto, as cidades grandes recebem montantes significativamente menores do fundo, ignorando o fato de que estas últimas apresentam maior demanda por recursos. Uma distribuição justa deveria estabelecer uma relação neutra (nem negativa, nem positiva), na qual todos os municípios pudessem usufruir de um patamar semelhante de recursos por habitante. Tal constatação é corroborada por Mendes, Miranda e Cosio (2008).

A abundância de recursos em algumas localidades, por um lado, e a escassez em outras localidades, por outro lado, proporcionam um cenário no qual as prefeituras estão mais propensas a apresentar uma gestão fiscal ineficiente. Da parte das prefeituras que recebem grande volume de recursos, em valores per capita, poderia existir uma espécie de moral hazard: "Se toda minha necessidade de financiamento é suprida pelas 
transferências da União, por que eu me esforçaria para obter mais recursos?”. Ou seja, há um incentivo implícito nas "regras do jogo" para a parte mais beneficiada não adotar medidas para melhorar sua gestão tributária e aumentar a arrecadação própria. Por outro lado, nas prefeituras que se deparam com menor orçamento de transferências, mas, ainda assim, defrontam-se com forte demanda por recursos, pode haver um estímulo ao desequilíbrio orçamentário, tornando corriqueiros expedientes como operações de créditos, restos a pagar e maquiagem contábil. Em qualquer um dos casos, não se observa um comportamento austero na condução de suas finanças.

\subsection{3 - Exclusividade do Critério Populacional}

Apesar de a população ser uma razoável proxy de demanda por recursos, bens e serviços públicos, a adoção exclusiva desta variável subestima o verdadeiro nível de necessidade dos municípios, além de ignorar a dimensão "capacidade" deles. Em tese, a aplicação do PIB per capita, que é verificada no FPM Capitais e no FPM Reserva, supriria esta última dimensão. Porém, a utilização do PIB per capita estadual - ao invés do PIB per capita municipal - e a baixa representatividade destas modalidades (Capitais e Reserva) no total do FPM não permitem apontar que este fundo capta efetivamente a dimensão de "capacidade" dos municípios.

Assim, outras variáveis deveriam ser incorporadas para melhor dimensionamento das dimensões "necessidade" e "capacidade" e sua relação. Com efeito, um critério mais justo deveria incluir: dados que efetivamente demonstrem a pressão que é exercida sobre o orçamento público, como a taxa de crescimento da população a densidade demográfica e a urbanização, e dados que pudessem captar o potencial de geração própria de recursos, como PIB per capita municipal e tamanho da base tributária (Mendes, 1994).

Contudo, é imperioso observar que há uma clara dificuldade operacional na ampliação das dimensões (e variáveis) a serem utilizadas no cômputo da partilha do FPM, especialmente do FPM Interior. Isto exigiria um maior esforço do Instituto Brasileiro de Geografia e Estatística (IBGE) no levantamento das informações relevantes, que se tornam significativamente mais complexas quando se trata da produção de estatísticas em âmbito municipal. Como as informações do FPM requerem uma atualização anual, isso exigiria ainda mais recursos para viabilizar esta produção de dados.

Uma possível solução para tal problema seria admitir que outros órgãos públicos participassem na produção destas estatísticas, como Secretaria do Tesouro Nacional (STN), Instituto Nacional de Estudos e Pesquisas Educacionais Anísio Teixeira (INEP) e Departamento de Informática do Sistema Único de Saúde (Datasus). Além disso, poderia ser admitida uma defasagem superior a um ano na produção destas informações.

\section{3 - Algumas Implicações da Distorção Distributiva do FPM}

É possível destacar alguns trabalhos na literatura nacional que avaliam como a distribuição iníqua do FPM impacta nas administrações municipais. A grande maioria destas publicações encontra evidências de efeitos sobre a qualidade do gasto público e o esforço de arrecadação tributária. Sobre o primeiro ponto, pode-se citar Mendes (2002), que aponta para uma tendência dos municípios mais beneficiados pelo fundo a aumentarem seus gastos em uma proporção superior ao incremento de receita própria, fato conhecido na literatura como flypaper effect (Fisher, 1982). Sobre o segundo ponto, há trabalhos mais recentes, como Mattos, Rocha e Avarte (2011), e mais antigos, como Tristão (2003). Em ambos os casos, a conclusão aponta para o FPM como fonte de ineficiência arrecadatória para as administrações locais, ou seja, proporciona um desincentivo para tributar.

Destacam-se ainda outros trabalhos aplicados com foco no FPM, mas com conclusões diversas, como por exemplo: Salto (2013), que procura verificar a capacidade redistributiva (regional) do FPE $^{\text {[xii] }}$, concluindo 
que este não apenas não contribui para reduzir a desigualdade como pode ser uma fonte de intensificação das disparidades regionais; Brollo, Nannicini, Perotti e Tabellini (2013), que encontram evidências da influência da distribuição do fundo nos níveis de corrupção local e na reeleição de prefeitos; e Litschig e Morrison (2013), ao avaliarem apenas municípios situados imediatamente acima dos limites das três primeiras faixas populacionais do fundo (municípios com maior FPM per capita), revelam um impacto positivo do FPM em indicadores educacionais e de pobreza destas localidades.

\section{3 - METODOLOGIA}

Rememorando que o objetivo deste artigo é avaliar se o FPM apresenta distorções na distribuição territorial de seus recursos, apresenta-se a metodologia de pesquisa proposta aqui: A Teoria dos Conjuntos Fuzzy. Essa teoria foi desenvolvida por Zadeh (1965) para tratar matematicamente situações envolvendo "graus de verdade". As funções fuzzy atribuem números reais, no intervalo entre $[0,1]$, a graus de verdade de afirmações, algo que não é definitivamente verdadeiro (1) ou falso (0) poderia assumir um valor de verdade intermediário entre estes dois extremos.

Tal teoria se presta a formalizar situações (conceitos, fenômenos, afirmações) envolvendo ambiguidade e imprecisão e acabou por exercer atração sobre economistas interessados na quantificação da pobreza. Há um grande número de trabalhos (nacionais e internacionais) utilizando tal metodologia para a apuração de pobreza multidimensional, desigualdade e desenvolvimento humano (Chiappero-Martinetti, 2000; Lelli, 2001; Baliamoune-Lutz, 2004; Lopes, 2003; Fonseca, 2003; Castro, Kerstenetzky \& Del-Vecchio, 2010). Sua utilização, no caso da estimação da pobreza, se justificaria por ser a pobreza um fenômeno inexato, permitindo atribuir às famílias classificações intermediárias entre "pobre" e "não pobre". Esta ferramenta também é comumente utilizada em análises de economia regional no Brasil (Simões, 2003; Cechini, Guilhoto, Hewings \& Chokri, 2012).

Não é complexa a adaptação do instrumental fuzzy para a proposta deste artigo. A necessidade de financiamento e o efetivo financiamento local são fenômenos imprecisos e, por isso, podem ser apurados segundo a teoria dos conjuntos fuzzy. Em outras palavras, é infactível apontar, de forma absoluta, se determinado município tem ou não suas necessidades atendidas pelo FPM: A maior parte dos municípios tem necessidade de financiamento, sendo a magnitude desta necessidade o ponto que os diferencia. Assim, pode-se atribuir a determinada localidade uma classificação intermediária entre a plena autonomia $(0)$ e a plena dependência (1), com relação ao FPM, verificando, assim, a capacidade redistributiva do fundo, objeto deste artigo.

Assim, de forma resumida, propõe-se a construção de dois índices baseados na teoria dos conjuntos fuzzy e de um indicador para verificar a relação entre esses dois índices. Sobre os índices fuzzy, o primeiro é o índice fuzzy de "necessidade fiscal" (doravante chamado de IFNF), que engloba em sua composição indicadores de demanda por serviços públicos e indicadores de geração autônoma de receita tributária; o segundo é o índice fuzzy do FPM (doravante, chamado de IFPM), que é composto, unicamente, por um indicador derivado do FPM. Por fim, a comparação (relação matemática) entre o IFNF e o IFPM permite apontar quais municípios recebem mais ou menos recursos do fundo, tendo em vista sua necessidade.

A aplicação desse instrumental justifica-se pelo amplo número de referências teóricas e aplicações práticas. Além disso, sua aplicação na área de finanças públicas - ao menos no Brasil - ainda é incipiente, tendo sido aplicada apenas por Castro e Afonso (2017), em análise sobre tributação patrimonial. 


\section{1 - Indicadores, Escopo Temporal e Geográfico}

Tendo em vista o perfil multidimensional da proposta deste artigo, foram selecionadas 11 (onze) variáveis primárias, que deram origem a 9 (nove) indicadores derivados. A escolha das variáveis visou atender às dimensões que procuram ser captadas pelos índices fuzzy em questão, ou seja, variáveis que possuíssem relação (direta ou inversa) com: Demanda por gastos públicos municipais, autonomia financeira (capacidade de geração própria de recursos) e, finalmente, recebimento de recursos de outras esferas de governo. As variáveis primárias foram obtidas para todos os municípios da amostra em duas fontes oficiais: Censo Demográfico de 2000 e 2010 (IBGE) e Finanças dos Municípios - Finbra (STN).

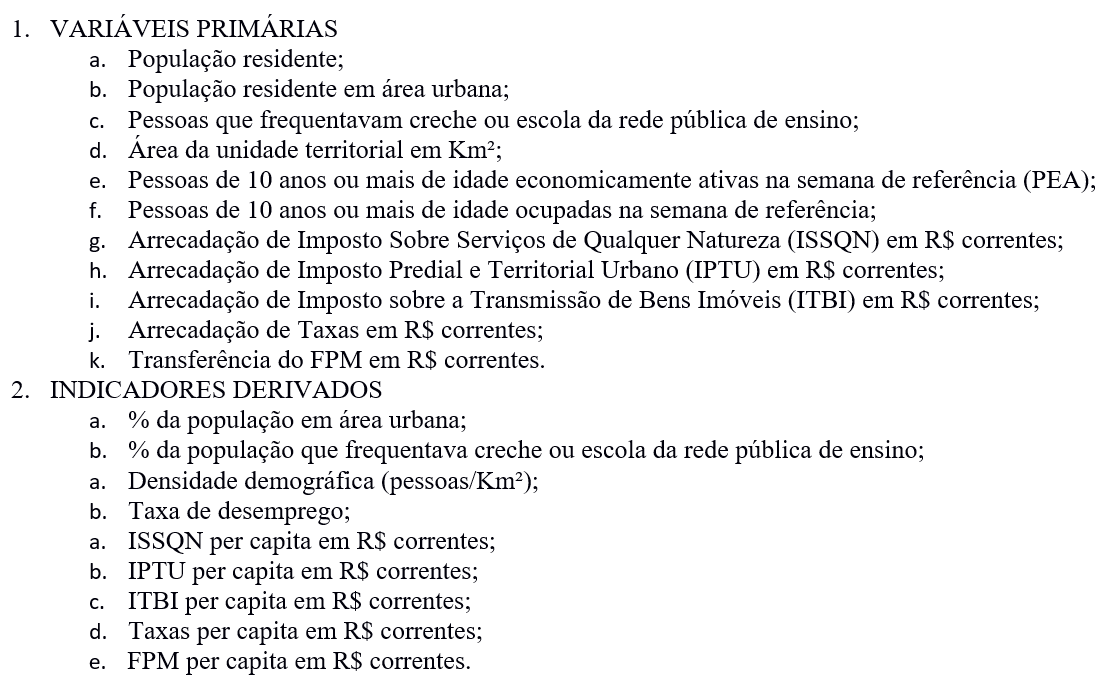

Dos indicadores derivados, os oito primeiros (da letra “a” à letra "h") foram utilizados na construção do IFNF e apenas o último (letra "i") foi utilizado na construção do IFPM. A relação dos indicadores derivados com o IFNF varia de acordo com a implicação daqueles na dimensão que se procura captar com este índice fuzzy. Em outras palavras, se um indicador derivado contribui para aumentar a "necessidade fiscal" do município, então ele tem relação positiva (direta) com o IFNF. Este é o caso dos indicadores listados da letra "a" à letra "d". Ao contrário, se um indicador derivado contribui para reduzir a "necessidade fiscal" do município, então ele tem relação negativa (inversa) com IFNF. Este é o caso dos indicadores listados da letra "e" à letra "h". Já no caso do IFPM, o único indicador derivado tem relação positiva (direta) com ele.

O termo "índice fuzzy" é utilizado de uma forma generalizada neste trabalho pois ele faz referência não apenas ao IFNF e ao IFPM, mas também aos índices construídos individualmente a partir de cada indicador derivado. Tendo isso em vista e com o objetivo de não haver confusão, esses índices fuzzy serão sempre citados através de suas siglas. Além destes, ainda podem ser citados na análise os índices fuzzy "individuais", que são calculados a partir de um único indicador derivado. São eles: Índice fuzzy de população em área urbana, índice fuzzy de população na rede de ensino público, índice fuzzy de densidade demográfica, índice fuzzy de desemprego, índice fuzzy de ISSQN per capita, índice fuzzy de IPTU per capita, índice fuzzy de ITBI per capita e índice fuzzy de taxas per capita.

A construção dos índices foi limitada aos anos 2000 e 2010, adequando-se, assim, a disponibilidade de parte das informações em nível municipal, oriunda do Censo Demográfico. Além disso, estipulou-se um limite geográfico para esta análise: Municípios compreendidos no território do estado de Minas Gerais. Esta escolha está relacionada a dois fatores: Primeiro, o montante de recursos do FPM atribuído às 27 (vinte e sete) unidades da federação seguia, até 2015, a mesma regra do FPE, não estando municípios de uma unidade da federação sujeitos à competição por recursos com municípios de outra unidade da federação; e segundo, 
Minas Gerais, devido a suas tão diversificadas características socioeconômicas e geográficas, é o estado que mais se aproxima das particularidades brasileiras, sendo a unidade da federação que melhor representa o país.

A princípio, todos os municípios existentes em Minas Gerais em 2000 e 2010 deveriam ser incluídos na apuração aqui proposta - ou seja, 853 (oitocentos e cinquenta e três) municípios. Entretanto, uma das fontes de dados, o Finbra, não apresentou informações para todos os municípios, mas apenas para uma amostra deles. Essa amostra, porém, é muito elevada, cobrindo a quase totalidade dos municípios e da população do estado. Em 2000 e 2010, respectivamente, o Finbra cobriu 98,8\% e 99,4\% dos municípios de Minas Gerais. Apesar de a amostra inicial ser excelente, optou-se por aplicar um filtro para excluir erros crassos, evitando, assim, problemas na construção dos indicadores derivados. Dessa forma, foram excluídos da base de dados os municípios que apresentaram valor nulo (zero ou inexistente) para qualquer uma das variáveis primárias, em qualquer um dos anos de análise. Por fim, excluiu-se da base de dados a capital mineira, Belo Horizonte, tendo em vista que esta não faz parte do FPM Interior (aplicado aos municípios que não a capital), mas ao FPM Capitais. Considerando estes fatores, a amostra de municípios reduziu-se para 753 (88,3\% do total), o que ainda é um número muito representativo.

\section{2 - CÁlCulo dos ÍNDiCES FuzzY}

A construção dos índices fuzzy foi feita a partir dos dados extraídos das fontes já citadas e utilizando uma das duas fórmulas básicas (Zadeh, 1965), que foram escolhidas conforme a relação do indicador derivado com o índice a ser construído (IFNF ou IFPM).

Para indicadores que estabelecem relação positiva com o índice, ou seja, quando o valor do indicador aumenta, o IFNF ou o IFPM aumenta, utilizou-se a seguinte fórmula para definir a função de pertinência:

$$
\begin{aligned}
& x_{i, j}=\frac{N_{j}-\operatorname{Min}_{j}}{\operatorname{Max}_{j}-\operatorname{Min}_{i}}, \quad 1<\mathrm{j}<9 ; 1<\mathrm{i}<753 \\
& x_{i, j}=\text { valor do índice fuzzy para o indicador } \mathrm{j} \text { calculado para o município } \mathrm{i} ; \\
& N_{j}=\text { valor observado da série do indicador } \mathrm{j} \text { para o município } \mathrm{i} ; \\
& \operatorname{Min}_{j}=\text { valor mínimo da série do indicador } \mathrm{j} ; \\
& \mathrm{Max}_{j}=\text { valor máximo da série do indicador } \mathrm{j} .
\end{aligned}
$$

Para indicadores que estabelecem relação negativa com o índice, ou seja, quando o valor do indicador aumenta, o IFNF diminui, utilizou-se a seguinte fórmula para definir a função de pertinência:

$$
\begin{aligned}
& x_{i, j}=\frac{\operatorname{Max}_{j}-N_{j}}{\operatorname{Max}_{j}-\operatorname{Min}_{j}}, \quad-1<\mathrm{j}<9 ; 1<\mathrm{i}<753 \\
& x_{i, j}=\text { valor do índice fuzzy para o indicador } \mathrm{j} \text { calculado para o município } \mathrm{i} ; \\
& N_{j}=\text { valor observado da série do indicador } \mathrm{j} \text { para o município } \mathrm{i} ; \\
& \operatorname{Min}_{j}=\text { valor mínimo da série do indicador } \mathrm{j} ; \\
& \operatorname{Max}_{j}=\text { valor máximo da série do indicador } \mathrm{j} .
\end{aligned}
$$

Para melhor ilustrar a relação entre os indicadores selecionados e os índices fuzzy agregados, o Quadro 01 a seguir foi construído: 
Quadro 01: Relação entre os Indicadores Derivados e o IFNF/IFPM

\begin{tabular}{lll}
\hline Indicador Derivado & IFNF & IFPM \\
\hline \% da população em área urbana & + & \\
\% da população que frequentava creche ou & + & \\
escola da rede pública de ensino & & \\
Densidade demográfica & + & \\
Taxa de desemprego & + & \\
ISSQN per capita & - & \\
IPTU per capita & - & \\
ITBI per capita & - & \\
Taxas per capita & - & \\
FPM per capita & & + \\
\hline
\end{tabular}

Os quatro primeiros indicadores do quadro anterior apresentam relação positiva com o IFNF. O primeiro indicador assume que quanto maior a parcela da população residindo no perímetro urbano do município, maior será a demanda por gastos correntes e investimentos na função urbanismo, aumentando a "necessidade fiscal" da prefeitura local. O segundo indicador assume que quanto maior a parcela da população utilizando os serviços educacionais públicos, maior será a demanda por gastos correntes e investimentos na função educação, aumentando a "necessidade fiscal" deste município. O terceiro indicador assume que quanto mais moradores em um espaço limitado, maior será a demanda por gastos correntes e investimentos nas funções transportes, segurança pública, saneamento, habitação e urbanismo, aumentando, da mesma forma, a "necessidade fiscal" local. O quarto indicador assume que quanto maior a taxa de desemprego local, maior será a demanda por gastos correntes e investimentos em assistência social, saúde, educação, segurança pública e transportes, aumentando a "necessidade fiscal" do município.

Os quatro indicadores seguintes (ISSQN per capita, IPTU per capita, ITBI per capita e Taxas per capita) apresentam relação negativa com o IFNF. Isso se dá pelo mesmo motivo nos quatro casos: Quanto maior a capacidade de uma prefeitura arrecadar tributos que estão sob sua competência, mais autônomo será o município, diminuindo sua "necessidade fiscal". Ou seja, menor será sua dependência de recursos oriundos de outras esferas de governo.

Por fim, o último indicador derivado (FPM per capita) tem relação positiva com o IFPM. Essa relação é óbvia, pois o IFPM é constituído por um único indicador. Quanto maior a receita de uma prefeitura a partir do FPM, maior será seu índice de "receitas intergovernamentais" (no caso, apenas do FPM).

Os índices construídos a partir da fórmula básica variam de 0 (zero) a 1 (um), onde 0 (zero) corresponde ao índice do município que apresenta o menor (maior) valor para dado indicador que estabelece relação positiva (negativa) com o IFNF ou IFPM, e 1 (um) corresponde ao índice do município que apresenta o maior (menor) valor para dado indicador que estabelece relação positiva (negativa) com IFNF ou IFPM.

Desta forma, deve-se atentar para o fato de que, esse índice de "grau de verdade" por utilizar o máximo de cada indicador como denominador, possui um risco de ser afetado por outliers. Como foram excluídos da amostra variáveis zeradas (nulas), não há risco de distorção pelo limite inferior dos dados. Porém, eventuais erros nos valores mais altos podem afetar os índices fuzzy individuais e, por consequência, o IFNF e o IFPM.

\section{3 - O Peso dos Indicadores}

Para se chegar ao resultado final do IFNF é preciso antes realizar a agregação dos índices fuzzy individuais, obtidos a partir de cada indicador trabalhado isoladamente. Contudo, para efetivar a agregação, é necessário identificar qual será a participação de cada um dos índices fuzzy individuais na composição final. Ou seja, deve-se obter o peso dos indicadores. 
A determinação dos pesos foi baseada em instrumental matemático. Esta escolha tem respaldo no fato de que, na maior parte dos estudos que utiliza a teoria dos conjuntos fuzzy, a escolha dos pesos é feita com base em instrumentais matemáticos (Diniz \& Diniz, 2009; Ottonelli \& Mariano, 2014), que são mais objetivos. $\mathrm{O}$ fato de não haver arbitragem na escolha dos pesos é a grande vantagem desta metodologia. Além disso, ela enfatiza a posição relativa, pressupondo que a relevância da situação fiscal da localidade é a comparação com os demais municípios. A "hierarquização" é obtida através da simples comparação.

Tendo isto como base, os pesos dos indicadores são calculados ponderados pelo tamanho da população dos municípios e com base na fórmula a seguir:

$w_{j}=$ peso do indicador $\mathrm{j}$;

$$
w_{j}=\ln \left[\frac{n}{\sum_{i=1}^{n} x_{i, j} n_{i}}\right]
$$

$x_{i, j}=$ valor do índice fuzzy para o indicador $\mathrm{j}$ calculado para o município $\mathrm{i}$;

$n$ =população total da amostra;

$n_{i}=$ população do município $\mathrm{i}$.

O objetivo da apuração do peso a partir dessa fórmula é evitar que os índices individuais com valores mais altos pesem mais no resultado agregado, o que poderia ocorrer em uma escolha arbitrária dos pesos. Com base nessa apuração de pesos, que permite uma ordenação completa (sem que dois indicadores apresentem o mesmo peso), se chega a seguinte classificação, para os dois anos inclusos na análise, representada na Tabela 04.

Tabela 4 - Peso dos Indicadores Derivados na Composição do IFNF

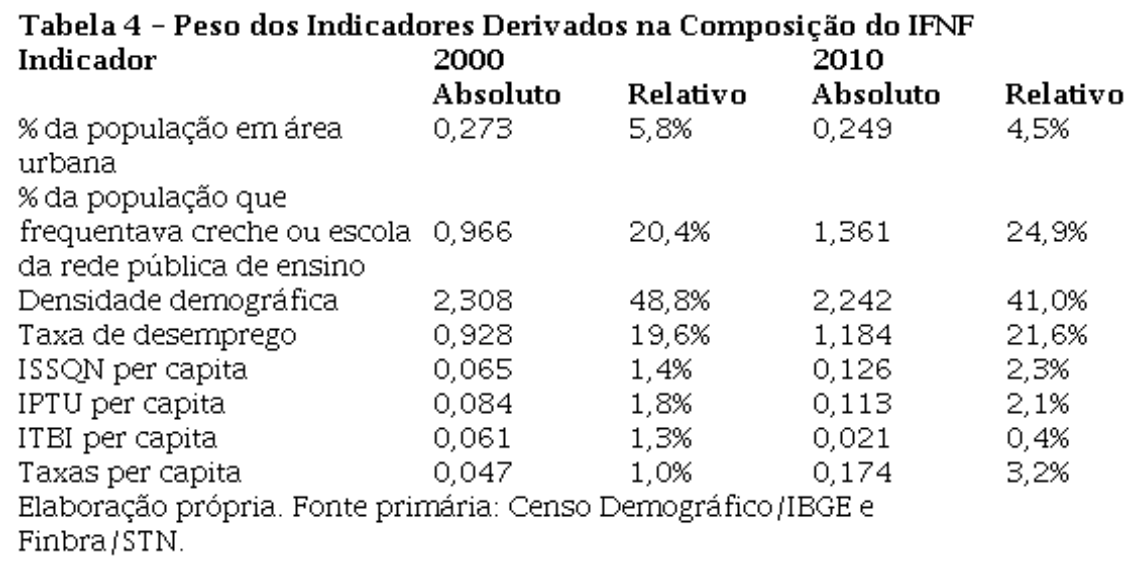

Elaboração própria. Fonte primária: Censo Demográfico/IBGE e Finbra/STN.

\section{4 - Construção do IFNF}

Para se obter finalmente o IFNF deve-se proceder com a agregação dos índices fuzzy individuais, ponderados por seus respectivos pesos. Trata-se apenas de uma média ponderada dos índices fuzzy, como pode ser notado na fórmula a seguir:

$x_{i, j}=$ valor do índice fuzzy para o indicador $\mathrm{j}$ calculado para o município $\mathrm{i}$;

$$
\mu_{i}=\frac{\sum_{j=1}^{n} x_{i, j} w_{j}}{\sum_{j=1}^{n} w_{j}}
$$

$w_{j}=$ peso do indicador $\mathrm{j}$. 
Com a agregação, apenas por uma coincidência um município apresentaria um IFNF de 0 (zero) ou 1 (um). Isso ocorre porque uma dada localidade dificilmente apresenta resultado extremos ( 0 ou 1$)$ em todos os indicadores selecionados. A probabilidade de encontrarmos um índice fuzzy agregado de 0 (zero) ou 1 (um) é cada vez menor quanto maior for o número de variáveis e de municípios a serem utilizadas na análise. Neste caso, em nenhum dos dois anos de análise um município obteve resultado 0 (zero) ou 1 (um) no IFNF. Deve destacar ainda que o IFPM não precisa ser agregado, pois ele tem apenas um componente.

É importante frisar, antes de se iniciar a análise de resultados, que o foco da análise recai sobre a relação matemática entre o IFNF e o IFPM, apesar de os resultados desses dois índices fuzzy também serem apresentados em separado. Como o primeiro mede a necessidade fiscal, a partir de uma ideia de hiato de orçamento, e o segundo mede a posição relativa de recebimento do FPM dentro do estado de Minas Gerais, assume-se que o resultado da divisão do IFNF pelo IFPM revela quais localidades estão sendo plenamente atendidas pelo fundo ou não. Se esta relação for maior que 1 (um), a necessidade fiscal é superior ao que é repassado pelo fundo, indicando que determinado município está recebendo menos do que deveria. Caso contrário, se a relação for menor do que 1 (um), a necessidade fiscal é inferior ao que é repassado, indicando que o local tem um excesso de recursos do fundo.

Com esta metodologia, não é possível - nem é a intenção do trabalho - determinar o tamanho deste déficit ou superávit ditado pelo FPM em cada local, mas apenas separar aqueles municípios prejudicados pelo atual critério de rateio, corroborando a noção geral de que o fundo, de fato, proporciona uma distribuição injusta.

Os resultados obtidos a partir da proposta metodológica dos conjuntos fuzzy são satisfatórios, na medida em que corroboram evidências que apontam para um padrão distorcido de distribuição de recursos pelo FPM. Contudo, é importante salientar suas limitaçóes. Em primeiro lugar, deve-se considerar a possibilidade de existência de inconsistências na base de dados do Finbra: Esta base é construída a partir da declaração de informações orçamentárias das prefeituras e o volume de dados exigidos é relativamente elevado e detalhado, o que pode proporcionar dificuldades operacionais para os governos locais nesta prestação de contas, conforme ressaltam Medeiros, Albuquerque, Diniz e Tavares (2014). Um segundo ponto está relacionado à escolha das variáveis para o cálculo dos índices fuzzy. Houve uma tentativa de captar, com estas variáveis, o maior número de dimensões possíveis que traduzissem o binômio "necessidade"-"capacidade". Porém, esta escolha possui caráter relativamente arbitrário. Como o intuito do artigo foi trazer mais uma contribuição para evidenciar os problemas dos critérios de partilha do FPM vigentes, reforçando o argumento de que a distribuição do fundo é injusta, estas limitações não parecem desqualificar os resultados obtidos.

\section{4 - RESULTADOS}

Há mais de uma forma de observar os resultados obtidos a partir da aplicação da metodologia proposta neste artigo. Por trabalhar com dados em painel - disposição de índices para diversos municípios em mais de um período do tempo -, a análise pode voltar-se para o comportamento do índice ou do município. Esta distinção, aqui, será captada pelas duas seções seguintes, que abordarão, respectivamente, os resultados agregados e o ranking dos municípios.

\section{1 - Resultados Agregados}

Os resultados agregados são apresentados na Tabela 05 que apresenta as estatísticas descritivas dos índices fuzzy dos municípios de Minas Gerais. 
Tabela 5 - Estatística Descritiva dos Índices Fuzzy - 2000 e 2010

\begin{tabular}{|c|c|c|c|c|c|c|}
\hline \multirow[t]{2}{*}{ Estatística } & \multicolumn{3}{|l|}{2000} & \multicolumn{3}{|l|}{2010} \\
\hline & IFNF & IFPM & IFNF/IFPM & IFNF & IFPM & IFNF/IFPM \\
\hline Máximo & 0,72 & 1,00 & $>100$ & 0,61 & 1,00 & $>100$ \\
\hline Mínimo & 0,14 & 0,00 & 0,18 & 0,16 & 0,00 & 0,26 \\
\hline Média & 0,26 & 0,21 & 1,27 & 0,27 & 0,18 & 1,45 \\
\hline Mediana & 0,25 & 0,16 & 1,57 & 0,25 & 0,14 & 1,81 \\
\hline Desvio Padrão & 0,06 & 0,15 & $>100$ & 0,06 & 0,13 & $>100$ \\
\hline
\end{tabular}

Elaboração própria. Fonte primária: Censo Demográfico/IBGE e Finbra/STN.

Chama a atenção inicialmente que a média e a mediana do IFNF são superiores às do IFPM nos dois anos de análise. Isto é, em geral, os municípios apresentam um índice de necessidade fiscal superior ao índice referente a receita do FPM, revelando uma distribuição ruim. Constata-se ainda que a relação IFNF/ IFPM aumentou, na média e na mediana, de 2000 a 2010, o que sugere que os principais problemas do fundo, como as faixas populacionais discretas, estão promovendo maior distorção com o passar dos anos. Comportamento semelhante também ocorre com o máximo e o mínimo do universo. Tal tendência já foi verificada anteriormente:

Os restos mortais ainda precariamente operantes do sistema (leia-se: sistema de distribuição do FPM interna aos estados), com toda certeza, tornaram-se um dispositivo ainda mais distorcido, na medida em que a urbanização e a metropolização continuaram se acentuando no país e o critério populacional viesado para pequenos municípios se tornou cada vez mais anacrônico e inadequado (Prado, 2006, p. 55, grifo nosso).

Importa notar que a piora na relação entre 2000 e 2010 é oriunda, quase que exclusivamente, da diminuição do IFPM, haja vista que o IFNF permaneceu praticamente inalterado no período. A piora da média e da mediana do índice fuzzy obtido a partir da distribuição do fundo só reforça a ideia de que sua divisão de recursos ficou ainda menos equânime ao longo do tempo, concentrando-se ainda mais em municípios com população muito pequena, viés corroborado por Mendes, Miranda e Cosio (2008). As estatísticas descritivas, apesar de servirem para dar uma boa noção geral dos resultados, não permitem uma fácil visualização da distribuição desses municípios com relação aos dois índices fuzzy em questão. Visando contribuir para melhorar tal percepção, a Figura 02 (referente ao ano 2000) e a Figura 03 (referente ao ano 2010) apresentam a dispersão da amostra de municípios entre os dois índices.

Figura 2 - IFNF x IFPM - 2000

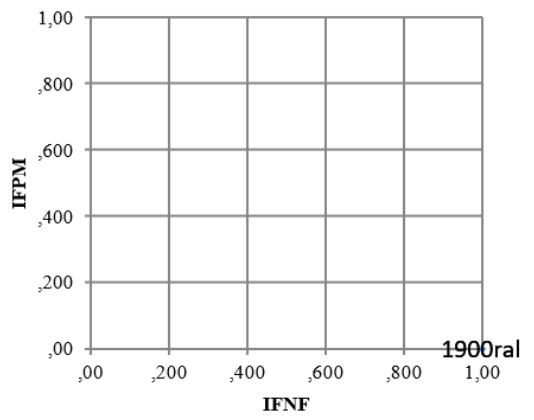

Figura 3 - IFNF x IFPM - 2010

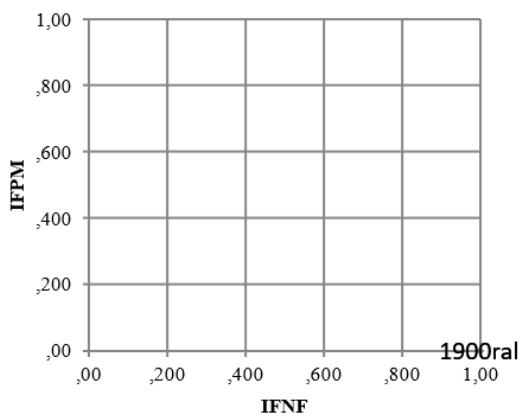

Elaboração própria. Fonte primária: Censo Demográfico/IBGE e Finbra/STN.

A linha reta diagonal das Figuras 02 e 03 determina os pontos nos quais o IFNF e o IFPM se igualam, estabelecendo o resultado unitário para sua relação. Esta seria a situação ideal, na qual um município aufere 
do fundo precisamente o que necessita, remetendo à concepção de "equalização fiscal" horizontal, na qual busca-se proporcionar a todos os cidadãos de um país o mesmo nível (ou algo próximo disso) de oferta e qualidade nos serviços públicos (Petchey \& Levtchenkova, 2007). Pontos estabelecidos abaixo da linha diagonal significam que o IFNF é superior ao IFPM, indicando vulnerabilidade fiscal a partir do fundo. Por outro lado, pontos acima da linha diagonal significam que o IFNF é inferior ao IFPM, indicando uma folga orçamentária proporcionada pelo fundo.

Nota-se, em ambas as figuras, que há uma concentração de pontos no cruzamento do intervalo $[0,2 ; 0,4]$ do IFNF com o intervalo [0,0;0,2] do IFPM, logo abaixo da linha diagonal. Em outras palavras, a maior parte dos municípios encontra-se em posição na qual seu hiato de orçamento não é compatível com o fluxo de recursos oriundos do FPM. Com efeito, o número de município que apresentou uma relação IFNF/IFPM superior a 1 foi de 559 (74,2\% do total), em 2000, e 606 (80,5\% do total), em 2010, revelando, mais uma vez, uma trajetória temporal depreciativa dos critérios de partilha do fundo. Estas informações podem ser visualizadas nas Figuras 04 e 05 a seguir.

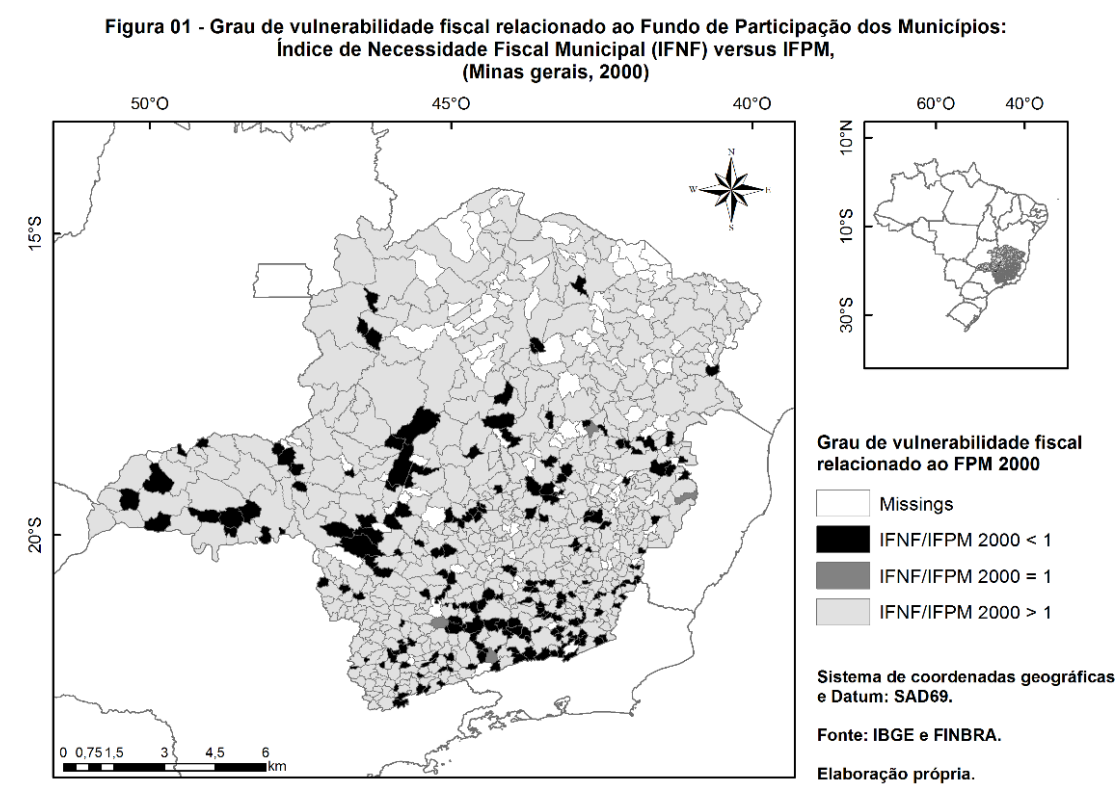

Figura 4 - Grau de Vulnerabilidade Fiscal Relacionado ao FPM: IFNF x IFPM - 2000 


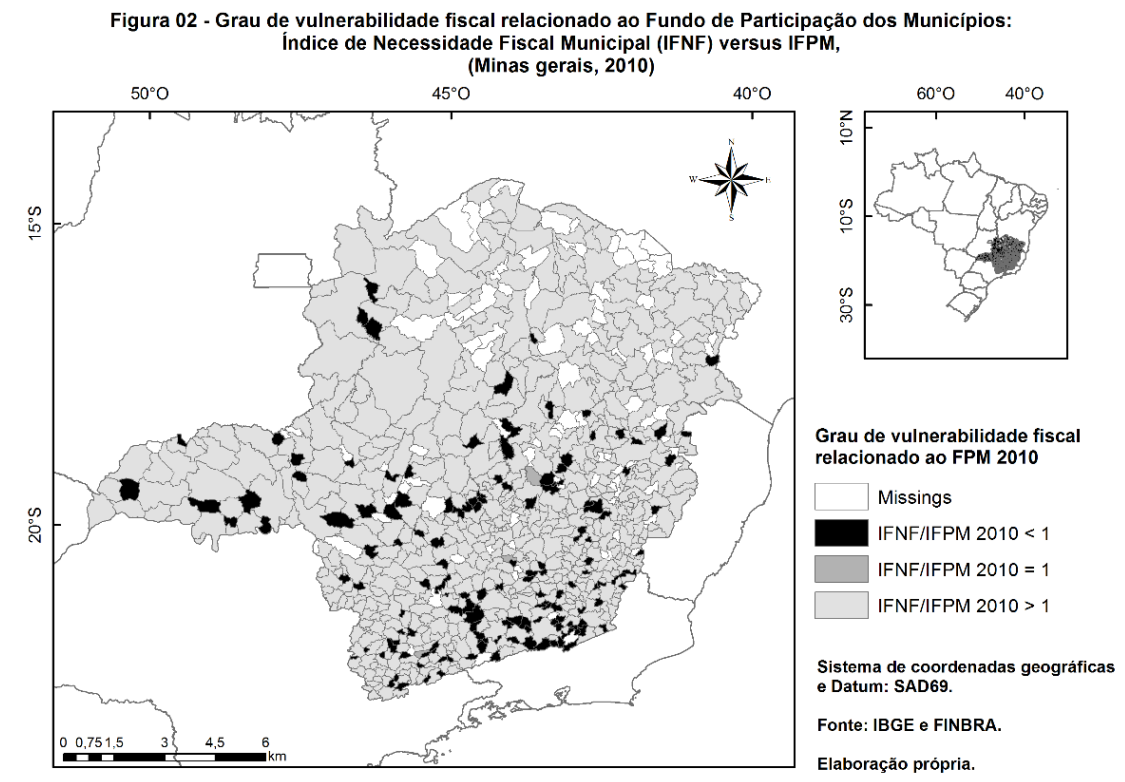

Figura 5 - Grau de Vulnerabilidade Fiscal Relacionado ao FPM: IFNF x IFPM - 2010

A tendência de agravamento das distorções distributivas do FPM ao longo do tempo é, provavelmente, o resultado mais importante obtido por este trabalho, haja vista que, apesar de outros autores já apontarem isso de forma teórica - como Prado (2006), na passagem destacada anteriormente -, poucos trabalhos se dedicaram a mostrar a distribuição do fundo em uma perspectiva dinâmica. A falta de atualizações nas faixas populacionais que determinam o coeficiente populacional dos municípios é a grande responsável por este problema: ao não acompanhar as mudanças socioeconômicas ocorridas no território, o critério se torna cada vez mais ultrapassado, enviesando ainda mais a distribuição de recursos.

A distribuição enviesada do FPM é particularmente preocupante, uma vez que o sistema de geração própria de receitas dos governos subnacionais (no qual se incluem os municípios) tem diversas falhas, que afetam a equidade e a competitividade horizontal (Ter-Minassian, 2012).

\section{2 - Ranking dos Municípios}

A segunda ótica de análise parte para uma observação mais individual: Elencar os municípios que se apresentam com os maiores e menores resultados a partir da relação IFNF/IFPM. As Tabelas 06 e 07 mostram as dez primeiras cidades que se localizam nos dois extremos do ranking. 
Tabela 6 - Rankings dos Índices Fuzzy - 2000

\begin{tabular}{|c|c|c|c|c|}
\hline Posição & Município & IFNF & IFPM & IFNF/IFPM \\
\hline 1 & Contagem & 0,72 & 0,00 & $>100$ \\
\hline 2 & Juiz de Fora & 0,27 & 0,00 & $>100$ \\
\hline 3 & Uberlândia & 0,27 & 0,00 & 85,66 \\
\hline 4 & Ribeirão das Neves & 0,56 & 0,02 & 32,52 \\
\hline 5 & Betim & 0,43 & 0,02 & 21,75 \\
\hline 6 & Ibirité & 0,59 & 0,03 & 19,82 \\
\hline 7 & Montes Claros & 0,31 & 0,02 & 16,22 \\
\hline 8 & Santa Luzia & 0,40 & 0,03 & 14,64 \\
\hline 9 & Vespasiano & 0,47 & 0,04 & 12,04 \\
\hline 10 & Sabará & 0,33 & 0,03 & 11,88 \\
\hline 744 & Antônio Prado de Minas & 0,23 & 0,74 & 0,31 \\
\hline 745 & $\begin{array}{l}\text { São Sebastião do Rio } \\
\text { Verde }\end{array}$ & 0,23 & 0,72 & 0,31 \\
\hline 746 & Olimpio Noronha & 0,19 & 0,63 & 0,31 \\
\hline 747 & $\begin{array}{l}\text { São Sebastião do Rio } \\
\text { Preto }\end{array}$ & 0,22 & 0,80 & 0,27 \\
\hline 748 & Pedro Teixeira & 0,22 & 0,79 & 0,27 \\
\hline 749 & Paiva & 0,24 & 0,88 & 0,27 \\
\hline 750 & Simão Pereira & 0,15 & 0,57 & 0,26 \\
\hline 751 & Soledade de Minas & 0,18 & 0,79 & 0,22 \\
\hline 752 & Cedro do Abaeté & 0,22 & 1,00 & 0,22 \\
\hline 753 & Doresópolis & 0,17 & 0,95 & 0,18 \\
\hline
\end{tabular}

Elaboração própria. Fonte primária: Censo Demográfico/IBGE e Finbra/STN. Importar tabla

Tabela 7 - Rankings dos Índices Fuzzy - 2010

\begin{tabular}{lllll}
\multicolumn{5}{l}{ Tabela 7 - Rankings dos Índices Fuzzy - 2010 } \\
Posição & Município & IFNF & IFPM & IFNF/IFPM \\
1 & Contagem & 0,61 & 0,00 & $>100$ \\
2 & Uberlândia & 0,23 & 0,00 & $>100$ \\
3 & Juiz de Fora & 0,22 & 0,00 & 66,41 \\
4 & Betim & 0,39 & 0,01 & 33,83 \\
5 & Ribeirão das Neves & 0,52 & 0,02 & 25,69 \\
6 & Montes Claros & 0,26 & 0,01 & 19,80 \\
7 & Ipatinga & 0,37 & 0,03 & 12,58 \\
8 & Vespasiano & 0,43 & 0,04 & 10,86 \\
9 & Governador Valadares & 0,25 & 0,03 & 10,00 \\
10 & Ibirité & 0,54 & 0,05 & 9,92 \\
744 & São Sebastião do Rio & 0,26 & 0,75 & 0,35 \\
745 & Preto & & & \\
746 & Agua Comprida & 0,20 & 0,60 & 0,34 \\
747 & Olaria & 0,21 & 0,60 & 0,34 \\
748 & São Sebastião do Rio & 0,19 & 0,57 & 0,34 \\
749 & Verde & & & \\
750 & Consolação & 0,24 & 0,69 & 0,34 \\
751 & Serranos & 0,20 & 0,60 & 0,33 \\
752 & Senador José Bento & 0,21 & 0,63 & 0,33 \\
753 & Doresópolis & 0,27 & 0,84 & 0,32 \\
Elaboração própria. Fonte primária: Censo Demográfico/IBGE e
\end{tabular}

Finbra/STN.

Elaboração própria. Fonte primária: Censo Demográfico/IBGE e Finbra/STN. Importar tabla 
Pelo lado dos dez municípios que apresentam a menor relação IFNF/IFPM em 2000 e 2010, ou seja, aqueles que combinam baixa necessidade com maior receita relativa do FPM, quatro localidades também figuram na lista de municípios menos populosos de Minas Gerais: Cedro do Abaeté, Doresópolis, Paiva e São Sebastião do Rio Preto, respectivamente, $2^{\mathrm{a}}, 4^{\mathrm{a}}, 5^{\mathrm{a}}$ e $6^{\mathrm{a}}$ menores cidades do estado, em termos demográficos. Para se ter uma dimensão de como o fator populacional influi na determinação deste resultado, basta notar que nenhum dos dez municípios que aparecem na parte de baixo do ranking exibido na Tabela 6, em 2000 ou em 2010, tem uma população superior a 3 mil habitantes. De acordo com uma tipologia de clusters criada por Tristão (2003), esses municípios são tipicamente rurais, têm alta dependência dos recursos do FPM e desempenho muito ruim da arrecadação tributária própria.

Voltando a atenção para a parte de cima do ranking, observa-se que, em 2000, sete dos dez municípios deste grupo faziam parte da Região Metropolitana de Belo Horizonte (RMBH); em 2010, cinco dos dez municípios faziam parte da $\mathrm{RMBH}$ e um (Ipatinga) fazia parte da Região Metropolitana do Vale do Aço (RMVA). Além disso, outras duas localidades que figuram nas primeiras posições nos dois anos são Uberlândia e Juiz de Fora. Ambas cidades estão entre as mais populosas de Minas Gerais (2a e $4^{a}$, respectivamente), são referências econômicas de suas respectivas mesorregiões (Triângulo Mineiro e Alto Paranaíba e Zona da Mata, respectivamente), além de se localizarem próximas às divisas com outros estados (São Paulo e Goiás, no primeiro caso, e Rio de Janeiro, no segundo), o que pode ser considerado um fator de maior dinamismo no fluxo de pessoas.

Tanto pela parte superior como pela parte inferior do ranking, os resultados aqui encontrados estão de acordo com as características de distribuição do FPM apresentadas por Gasparini e Miranda (2006): Os maiores beneficiários são, invariavelmente, aquelas localidades com populações pequenas e os menores beneficiários, municípios grandes de regióes metropolitanas.

Os resultados obtidos deixam claro o quão falho é o critério do fundo para dimensionar as necessidades das localidades. Quase todas as cidades que aparecem no topo do ranking caracterizam-se pela alta concentração populacional, com consequente elevada demanda por recursos públicos. Mesmo com tanta disponibilidade de fatores de produção - especialmente trabalho -, muitas destas localidades não conseguem transformar este potencial em ganhos econômicos e tributários, servindo como uma espécie de "suporte" aos centros econômicos mais dinâmicos.

Tal situação remete à ideia de "cidades dormitórios", um conceito que sintetiza as carências locais e impõe aos seus trabalhadores a necessidade de grandes deslocamentos diários entre moradia e trabalho (Lago, 2007). Essas localidades normalmente encontram-se no entorno de algum centro econômico-financeiro e servem de "dormitório" para os trabalhadores da cidade com alto nível de atividade (centro). Desta forma, essas cidades possuem uma demanda elevada por serviços públicos, pois suas populações são grandes, porém têm baixa capacidade de gerar receita própria, uma vez que seus habitantes exercem suas atividades produtivas no município vizinho. A baixa base para arrecadação de ISSQN e o pequeno volume de FPM per capita das "cidades dormitório" cria uma situação de restrição orçamentária e de carência de atuação estatal nessas localidades. Usualmente, as cidades do entorno das regiões metropolitanas, como é o caso de Contagem, Ribeirão das Neves, Betim, Ibirité e Vespasiano, são as principais afetadas por esses problemas.

\section{5 - CONSIDERAÇÕES FINAIS}

Desde sua regulamentação mais recente, em 1989, o FPM teve suas regras de distribuição de recursos criticada por especialistas. O baixo esforço político para reverter tal quadro perpetuou uma divisão injusta dos recursos do fundo, que leva parte dos municípios a deparar-se com uma situação de vulnerabilidade fiscal.

Assumindo a hipótese de que os critérios de rateio do FPM proporcionam uma partilha ineficiente de seus recursos, este artigo objetivou aplicar um instrumental matemático (teoria dos conjuntos fuzzy) para verificar o padrão de distribuição desse fundo entre os municípios de Minas Gerais em dois períodos do tempo (os 
anos de 2000 e 2010). Para isso, foram construídos dois índices fuzzy - um relacionado à ideia de "necessidade fiscal" e outro que relativizou a partilha do FPM no estado - que, relacionados matematicamente, indicavam quais localidades estariam recebendo recursos aquém ou além do necessário.

Os resultados agregados mostraram que, em média, os municípios mineiros apresentaram um nível de necessidade fiscal superior ao repassado pelo fundo e esta relação piorou de 2000 a 2010, ponto que se julga ser muito relevante, por evidenciar como a partilha do fundo tende a acentuar suas distorções ao longo do tempo. Os resultados individuais mostraram que os municípios com contingente populacional elevado e que estão localizados em regiões metropolitanas são aqueles menos atendidos pelo FPM. Ou seja, apesar de sua maior demanda por recursos, estes locais recebem relativamente menos do fundo. Até como consequência da fórmula de cálculo do FPM Interior, o fator populacional foi determinante nos resultados, haja vista que municípios demograficamente muito pequenos foram os mais beneficiados com a partilha.

Este artigo procura contribuir para reforçar as evidências de que o FPM apresenta um padrão de distribuição que não atende sua meta redistributiva. Assim, conclui-se que é imprescindível ao sistema federativo brasileiro rever as regras do fundo e que o momento atual, no qual a crise fiscal leva a um natural debate em torno da tributação e das relações entre esferas de governo, seria um momento oportuno para inserir tal tema na agenda de reformas que o país precisa.

\section{REFERÊNCIAS BIBLIOGRÁFICAS}

Afonso, J.R.; Castro, K.P. (2016). Carga Tributária en Brasil: Redimensionada y Repensada. Revista de Administración Tributaria CIAT, 40, 1-16.

Afonso, J.R.; Pinto, V.C.; Guimarães Junior, J.R.L. (2017). Antecipando os números oficiais da Arrecadação Federal: resultados para dezembro de 2016: Melhor do que foi em 2016, mas ainda o pior Dezembro. Boletim Informativo FGV/IBRE, (s.n.).p. 26.

Afonso, J.R.; Soares, J.M.; Castro, K.P. (2013). Evaluation of the Structure and Performance of the Brazilian Tax System: White Paper on Taxation in Brazil [Discussion Paper IDB-DP No 265]. Brasília, DF: BID.BaliamouneLutz, M. (2004). On the measurement of human well-being: fuzzy set theory and Sen's capability approach [WIDER Research Paper, No 16]. Tokyo: United Nations University.

Boadway, R.; Roberts, S.; Shah, A. (1993). The reform of fiscal systems in developing countries: a federalism perspective. Apresentação no Simpósio Internacional sobre Reforma Fiscal, São Paulo, SP, Brasil, 1.

Brandt, C.T. (2010). A criação de municípios após a Constituição de 1988: O impacto sobre a repartição do FPM e a Emenda Constitucional no 15, de 1996. Revista de Informação Legislativa, 47(187), 59-75.

Brollo, F.; Nannicini, T.; Perotti, R.; Tabellini, G. (2013). The political resource curse. American Economic Review, 103(5), 1759-1796.

Castro, K.P.; Afonso, J.R. (2017). IPTU: Avaliação de Potencial e Utilização Sob a Ótica da Teoria dos Conjuntos Fuzzy. Rev. Adm. Pública, 51(5), 828-853.

Castro, K.P.; Kerstenetzky, C.L.; Del-Vecchio, R. (2010, setembro). Pobreza Fuzzy Multidimensional: Uma Análise das Condições de Vida na Zona Oeste do Rio de Janeiro - 1991 e 2000. Anais do Simpósio Brasileiro de Pesquisa Operacional, Bento Gonçalves, RS, Brasil, 42.

Cechini, K.; Guilhoto, J.M.; Hewings, G.J.D.; Chokri, D. (2012). Brazilian automotive industry in the nineties [MPRAPaper, No 41197]. Munich.

Chiappero-Martinetti, E. (2000). A multidimensional assessment of well-being based on Sen's functioning approach. Rivista Internazionale di Scienze Sociali, 2, 207-239.

Diniz, M.B.; Diniz, M.M. (2009). Um indicador comparativo de pobreza multidimensional a partir dos objetivos do desenvolvimento do milênio. Economia Aplicada, 13(3), 399-423.

Federação das Indústrias do Estado do Rio de Janeiro. (2017). A Situação Fiscal dos Estados Brasileiros. Pesquisa e Estudos Socioeconômicos FIRJAN, (s.n.).p. 10. 
Fisher, R.C. (1982). Income and grant effects on local expenditure: The flypaper effect and other difficulties. Journal Of Urban Economics, 12(3), 324-345.Fonseca, O.L.H. (2003). Aplicação de Métodos de Análise Espacial e da Teoria dos Conjuntos Nebulosos em Estudos sobre Pobreza (Dissertação de Mestrado). UFRJ, Rio de Janeiro, RJ, Brasil.

Gasparini, C.E.; Miranda, R.B. (2006). Evolução dos aspectos legais e dos montantes de transferências realizadas pelo Fundo de Participação dos Municípios [Texto para Discussão No 1243]. Brasília: IPEA.

Gomes, G. M.; Macdowell, M. C. (2000). Descentralização Política, Federalismo Fiscal e Criação de Municípios: O que é Mau para o Econômico nem Sempre é Bom para o Social [Texto para Discussão No 706]. Brasília: IPEA.

Lago, L.C. (2007). A "periferia" metropolitana como lugar do trabalho: da cidade-dormitório à cidade plena. Cadernos IPPUR, XXI(2), 9-28.

Lelli, S. (2001). Factor analisys vs. fuzzy sets theory: assessing the influence of different techniques on Sen's functioning approach [Public Economics Working Paper Series No 121]. Leuven: Center for Economic Studies.

Litschig, S.; Morrison, K. (2013). The impact of intergovernmental transfers on education outcomes and poverty reduction. American Economic Journal: Applied Economics, 5(4), 206-240.

Lopes, H.M. (2003). Análise de Pobreza com Indicadores Multidimensionais: Uma Aplicação para Brasil e Minas Gerais (Dissertação de Mestrado). UFMG, Belo Horizonte, MG, Brasil.

Mattos, E.; Rocha, F.; Avarte, P. (2011). Flypaper effect revisited: evidence for tax collection efficiency in Brazilian municipalities. Estudos Econômicos, 41(2), 239-267.

Medeiros, K.R.; Albuquerque P.C.; Diniz, G.T.N.; Tavares, R.A.W. (2014). Bases de dados orçamentários e qualidade da informação: uma avaliação do Finanças do Brasil (Finbra) e do Sistema de Informações sobre Orçamentos Públicos em Saúde (Siops). Rev. Adm. Pública, 48(5), 1113-1133.

Mendes, M. (1994). Proposta para um novo federalismo fiscal: Novos critérios de distribuição para o FPM e criação do Fundo de Participação das Regiões Metropolitanas (Consultoria de Acompanhamento e Análise das Finanças Públicas/1994), Brasília, DF, Banco Central do Brasil.

Mendes, M. (2002). Descentralização fiscal baseada em transferências e captura de recursos públicos nos municípios brasileiros (Tese de Doutorado). USP, São Paulo, SP, Brasil.

Mendes, M.; Miranda, R.B.; Cosio, F.B. (2008). Transferências intergovernamentais no Brasil: diagnóstico e proposta de reforma [Texto Para Discussão No 40]. Brasília: Senado Federal.

Monastério, L.M. (2014). A Estranha Distribuição da População dos Pequenos Municípios Brasileiros. Rev. Econ. NE, Fortaleza, 45(4), 111-119.

Monteiro Neto, A. (2014). Federalismo sem pactuação: Governos estaduais na antessala da federação [Texto para Discussão No 1961]. Brasília: IPEA.

Ottonelli, J.; Mariano, J.L. (2014). Pobreza multidimensional nos municípios da Região Nordeste. Rev. Adm. Pública, 48(5), 1253-1279.

Petchey, J.D.; Levtchenkova, S. (2007). Fiscal Capacity Equalization and Economic Efficiency: The Case of Australia. In: Martinez-Vazquez, J., Searle, B. (Ed.). Fiscal Equalization: Challenges in the Design of Intergovernmental Transfers (pp.13-30). New York: Springer.

Prado, S. (Org.). (2006). Transferências Intergovernamentais na Federação Brasileira: Avaliação e Alternativas de Reforma [Caderno Fórum Fiscal No 6]. Brasília: Fórum Fiscal dos Estados Brasileiros.

Rezende, F. (2010). Federalismo fiscal: em busca de um novo modelo. In: Santana, W., Oliveira, R.P. (Org.). Educação e federalismo no Brasil: combater as desigualdades, garantir a diversidade (pp. 71-88). Brasília: Unesco.

Salto, F.S. (2013). A economia política das transferências fiscais no Brasil: o Fundo de Participação dos Estados (FPE) contribuiu no processo de redução das disparidades regionais entre 1985 e 2009? (Dissertação de Mestrado). EAE/FGV, São Paulo, SP, Brasil.

Secretaria do Tesouro Nacional. (2016a). Boletim das Finanças Públicas dos Entes Subnacionais. Brasília: STN.

Secretaria do Tesouro Nacional. (2016b). Comunicado Decendial: FPM / FPE / IPI-Exp / FUNDEB - Junho/2016. Brasília: STN. 
Serra, J., Afonso, J.R. (2007). El federalismo fiscal en Brasil: una visión panorámica. Revista de La Cepal, 91, 29-52.

Souza Neto, M.L.; Ferreira, L.O.G. (2015, setembro). Por Uma Verdadeira Mudança no FPE. Anais do Congresso UFSC de Iniciação Científica em Contabilidade, Florianópolis, SC, Brasil, 6.

Simões, R.F. (2003). Complexos industriais no espaço: uma análise de fuzzy cluster [Texto para discussão No 209]. Belo Horizonte: CEDEPLAR.

Ter-Minassian, T. (2012). Reforming the Revenue-Sharing Fund for the States (FPE) [Discussion Paper IDB-DP No 216], Brasília, DF: BID.

Ter-Minassian, T.; Mello, L. (2016). Intergovernmental Fiscal Cooperation: International Experiences and Possible Lessons for Brazil [Technical Note IDB-TN No 1048]. Brasília, DF: BID.

Tribunal de Contas da União. (2016). FPM - Decisão Normativa 157/2016 (Exerc. 2017). Brasília: TCU.

Tristão, J.A.M. (2003). A administração tributária dos municípios brasileiros: Uma avaliação do desempenho da arrecadação (Tese de Doutorado). EAE/FGV, São Paulo, SP, Brasil.

Zadeh, L.A. (1965). Fuzzy Sets. Information and Control, 8, 338-353.

\section{Notas}

[i]A "receita disponível" de uma esfera de governo é o resultado da soma de sua arrecadação própria com as transferências constitucionais líquidas (transferências recebidas menos transferências concedidas).

[ii]As estatísticas referentes à distribuição do FPM e arrecadação da CSL

[iii]Lei Complementar no 62 de 28 de dezembro de 1989. Disponível em: http://www.planalto.gov.br/ccivil_03/leis/LCP/ Lcp62.htm .

[iv]Lei Complementar $n^{\circ}$ 143, de 17 de julho de 2013. Disponível em: http://www.planalto.gov.br/ccivil_03/leis/LCP/ Lcp143.htm .

[v]O Estado de Alagoas impetrou a ADIN no 5.069-DF contra as mudanças na Lei, argumentando que o novo texto manteve vícios idênticos aos da legislação original, declarada inconstitucional pelo Acórdão de 24 de fevereiro de 2010 do STF. Esta ação encontra-se aguardando julgamento, conforme despacho proferido em 6 de dezembro de 2013 por aquela Corte.

[vi]Lei no 5.172 de 25 de outubro de 1966. Disponível em: http://www.planalto.gov.br/ccivil_03/leis/L5172.htm .

[vii]Art. 15 da Constituição dos Estados Unidos do Brasil de 1946.

[viii]Emenda Constitucional no 55 de 20 de setembro de 2007. Disponível em: http://www.planalto.gov.br/ccivil_03/ Constituicao/Emendas/Emc/emc55.htm .

[ix]Municípios da Reserva são aqueles com população superior a 156.216 habitantes.

[x]Art. 2, \$2 : "Os critérios de rateio do Fundo de Participação dos Estados e do Distrito Federal, a vigorarem a partir de 1992, serão fixados em lei específica, com base na apuração do censo de 1990".

[xi]Disponível em: http://www.stf.jus.br/portal/cms/verNoticiaDetalhe.asp?idConteudo=120714\&caixaBusca=N .

[xii]A conclusões de Salto (2012) podem ser estendidas para o FPM, haja vista que o fundo municipal compartilha a mesma característica do fundo estadual no que toca à divisão não dinâmica de recursos entre UFs.

\section{BY-NC-ND}

